Jakub MATUSZAK ${ }^{1}$

Kazimierz ZALESKI ${ }^{2}$

\title{
ANALIZA SIE W PROCESIE OBRÓBKI KRAWĘDZI SZCZOTKAMI CERAMICZNYMI
}

\begin{abstract}
Zjawisko formowania się zadziorów jest nieodzownym elementem procesu skrawania. Narzędziami przeznaczonymi do usuwania zadziorów są szczotki z włóknami ceramicznymi. Istnieje wiele czynników zmiennych związanych z konstrukcją szczotek ceramicznych, które dobiera się w zależności od rodzaju materiału obrabianego, wielkości zadziorów i spodziewanych efektów obróbki. Do czynników zmiennych zalicza się: rodzaj włókna ceramicznego, wartość wysunięcia włókien z tulei korpusu, sztywność sprężyny uchwytu kompensacyjnego. Poza zmiennymi wynikającymi z konstrukcji szczotek, podczas procesu można dodatkowo sterować parametrami technologicznymi (prędkość posuwu, prędkość skrawania i dosuw). W pracy analizowano wpływ wybranych czynników konstrukcyjnych szczotek ceramicznych na siłę osiową w procesie szczotkowania. Do badań użyto próbek prostopadłościennych wykonanych ze stopu aluminium 7075. Badania przeprowadzono na autorskim siłomierzu tensometrycznym o częstotliwości próbkowania $80 \mathrm{~Hz}$. Szczotkowano płaską powierzchnię próbek ustawioną prostopadle do osi narzędzia. Wykazano, że dla ustalonych w eksperymencie warunków procesu w większym stopniu na wartość siły osiowej wpływa rodzaj zastosowanej sprężyny w uchwycie kompensacyjnym niż rodzaj zastosowanego włókna.
\end{abstract}

Słowa kluczowe: zadziory, siła skrawania, szczotki ceramiczne, amplituda siły

\section{Wprowadzenie}

W procesie obróbki skrawaniem pokonanie przez narzędzie oporów odkształceń sprężystych i plastycznych prowadzi do oddzielania warstwy skrawanej i przekształcania jej w wiór. Gdy narzędzie zbliża się do krawędzi próbki, wióry, które nie zostają odseparowane od materiału rodzimego, a ich podstawa jest połączona z materiałem obrabianym w obszarze krawędzi, są traktowane jako zadziory. Innym czynnikiem prowadzącym do powstawania zadziorów są silne odkształcenia plastyczne o dużej prędkości, towarzyszące typowym procesom obróbki skrawaniem, takim jak toczenie, frezowanie. Wychodzące z materiału narzędzie może prowadzić do odkształceń warstwy wierzchniej w pobliżu krawę-

\footnotetext{
${ }^{1}$ Autor do korespondencji/corresponding author: Jakub Matuszak, Politechnika Lubelska, ul. Nadbystrzycka 36, 20-618 Lublin, tel.: 815384707, e-mail: j.matuszak@ pollub.pl

${ }^{2}$ Kazimierz Zaleski, Politechnika Lubelska, e-mail: k.zaleski@pollub.pl
} 
dzi materiału obrabianego, co także jest rozumiane jako zadzior [1]. Te dwa zjawiska mogą występować niezależnie podczas procesu skrawania. Ponadto różna skrawalność materiałów obrabianych sprawia, że zadziory powstałe podczas procesów obróbki ubytkowej przyjmują różne kształty i wysokość. W literaturze można spotkać wiele klasyfikacji zadziorów w zależności od kształtu, miejsca występowania czy zjawisk towarzyszących procesowi ich formowania $[4,7]$. $\mathrm{Z}$ uwagi na częste występowanie niekorzystnego zjawiska pojawiania się zadziorów, istnieje wiele metod usuwania zadziorów oraz kształtowania krawędzi $[2,3]$. Wybór optymalnej metody obróbki krawędzi jest związany nie tylko z właściwościami materiału czy wielkością zadziorów, ale także wymaga uwzględnienia kształtu i rozmiaru przedmiotu obrabianego. Ze względu na stopień zmechanizowania, metody obróbki krawędzi można podzielić na ręczne, ręczno-maszynowe i maszynowe.

Metody ręczne są stosowane głównie w produkcji jednostkowej. Do usunięcia zadziorów są wykorzystywane pilniki, skrobaki i gratowniki o różnej geometrii. Obróbka ręczna jest czasochłonnym procesem o małej powtarzalności, a jej koszt podnosi konieczność wydzielenia w zakładach dodatkowych stanowisk ślusarskich. Obróbka ręczno-maszynowa jest popularna z uwagi na szeroki dostęp szybkoobrotowych narzędzi o napędzie elektrycznym lub pneumatycznym. Część roboczą tych narzędzi stanowią najczęściej ściernice, szczotki druciane czy taśmy ścierne.

Obróbka maszynowa stanowi najbardziej rozwiniętą grupę metod obróbki krawędzi. Jest to związane z automatyzacją procesu i dużą wydajnością [5]. W tej grupie istnieje wiele metod, które opierają się na działaniu medium ściernego. W obróbce wibrościernej są stosowane różnego rodzaju kształtki ścierne o określonej twardości, uzależnionej od rodzaju materiału obrabianego oraz o gabarytach dopasowanych do przedmiotu obrabianego. Medium ścierne jest także wykorzystywane w obróbce przetłoczno-ściernej i magnetościernej. Można również wyróżnić metody termiczne, chemiczne, elektrochemiczne. Na obrabiarkach sterowanych numerycznie jest możliwa maszynowa obróbka krawędzi przy użyciu frezów, fazowników, szczotek drucianych czy ceramicznych. Włókna szczotek drucianych, uderzając w powierzchnię obrabianą, mogą dodatkowo wprowadzić korzystne zmiany w warstwie wierzchniej stref przykrawędziowych.

Wykorzystując fakt zamocowania przedmiotu na stole obrabiarki po przeprowadzonym procesie frezowania, warto przeprowadzić obróbkę polegającą na usunięciu zadziorów narzędziami mocowanymi w uchwycie wrzeciona. Narzędziami dedykowanymi do tego procesu są szczotki, których część robocza jest zbudowana z pęków włókien na bazie tlenku glinu. Mikrowłókna szczotek ze względu na ich dużą liczbę (każde włókno może się składać z ok. 1000 mikrowłókien [9]) i elastyczność są w stanie dopasować się do kształtu obrabianego przedmiotu, co jest szczególnie korzystne w przypadku elementów cienkościennych o małej sztywności. Producent w swojej ofercie posiada kilka odmian włókien. W celu ułatwienia wyboru, produkowane włókna mają różną kolorystykę, 
w zależności od materiału obrabianego, przeznaczenia i spodziewanych efektów [9]. Wymienne włókna, stanowiące element roboczy narzędzia, mocuje się w uchwycie kompensacyjnym wyposażonym w sprężynę. Dostępne są dwie sprężyny różniące się sztywnością. Wybór sprężyny, podobnie jak wybór rodzaju włókna, także wpływa na efekty obróbki. Narzędzia te można wykorzystywać nie tylko do obróbki krawędzi, ale także do oczyszczania powierzchni, zmniejszania chropowatości powierzchni czy też uzyskiwania powierzchni o określonym układzie kierunkowości.

W pracy [6] przedstawiono wyniki badań chropowatości powierzchni po szczotkowaniu otworów powstałych w procesie wiercenia wiertłami ze stali szybkotnącej oraz węglików spiekanych w stopie magnezu AM60. Wykazano, że największy spadek chropowatości w stosunku do procesu wiercenia uzyskano już w pierwszym przejściu szczotki ceramicznej, a dalsze zwiększanie liczby przejść nie jest już tak efektywne.

Autorzy pracy [8] przedstawili wyniki badań chropowatości powierzchni po obróbce stopu niklu, stali oraz stopu aluminium. Wykazano wpływ prędkości posuwu i liczby przejść na chropowatość powierzchni, co jest zbieżne z zaleceniami producenta. $Z$ uwagi na niewielką liczbę prac badawczych dotyczących obróbki szczotkami ceramicznymi oraz brak analizy sił podczas obróbki, w artykule podjęto próbę analizy wpływu rodzaju włókna ceramicznego szczotki na siły w procesie szczotkowania.

\section{Metodyka badań}

Badania sił w procesie szczotkowania przeprowadzono na frezarskim pionowym centrum obróbkowym HX712G ze sterowaniem firmy Fanuc. Do badań użyto czterech szczotek ceramicznych, różniących się właściwościami, których parametry przedstawiono $\mathrm{w}$ tab. 1 . Zróżnicowanie cech narzędzi polegało na zastosowaniu włókien o różnej elastyczności i gęstości upakowania w pęku. Średnica pęku włókien wynosiła $6 \mathrm{~mm}$. Ponadto zastosowano dwie wymienne sprężyny w uchwycie kompensacyjnym o różnej sztywności. Jako materiał obróbkowy wykorzystano próbki ze stopu aluminium 7075 o wymiarach 50x15x5 mm. Powierzchnia obrabiana była ustawiona prostopadle do osi szczotki. Dla wszystkich włókien zachowano stałą wartość wysunięcia z uchwytu kompensacyjnego, równą $5 \mathrm{~mm}$. Badania przeprowadzono z zachowaniem stałych parametrów technologicznych szczotkowania: $v_{c}=94 \mathrm{~m} / \mathrm{min}, v_{f}=1000 \mathrm{~mm} / \mathrm{min}, a_{p}=0,5 \mathrm{~mm}$. Badania prowadzono przy użyciu autorskiego siłomierza z zastosowaniem belki tensometrycznej o symbolu NA1, pozwalającej na pomiary sił do ok. 400 N. Stanowisko pomiarowe przedstawiono na rys. 1. 
Tabela 1. Widok narzędzi użytych podczas eksperymentu

Table 1. View of the tools used during the experiment

\begin{tabular}{|c|c|c|c|}
\hline \multicolumn{4}{|c|}{ Kolor włókien } \\
\hline różowe & czerwone & białe & niebieskie \\
\hline \multicolumn{4}{|c|}{ przeznaczenie } \\
\hline $\begin{array}{l}\text { najbardziej miękkie } \\
\text { i elastyczne wókna } \\
\text { - delikatna obróbka }\end{array}$ & $\begin{array}{c}\text { wysoka elastyczność } \\
\text { włókna - gratowanie, } \\
\text { efekt polerowania }\end{array}$ & $\begin{array}{l}\text { sztywniejsze włókno, } \\
\text { wyższa efektywność - } \\
\text { gratowanie, zmniejsza- } \\
\text { nie chropowatości }\end{array}$ & $\begin{array}{l}\text { najbardziej sztywne } \\
\text { włókno, wysoka efek- } \\
\text { tywność - obróbka ma- } \\
\text { teriałów trudnoobra- } \\
\text { bialnych }\end{array}$ \\
\hline \multicolumn{4}{|c|}{ widok rzeczywisty } \\
\hline 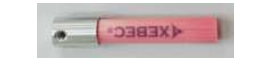 & - & 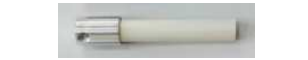 & \pm \\
\hline \multicolumn{4}{|c|}{ uchwyt kompensacyjny z zamocowanym włóknem } \\
\hline & SEBEC & & \\
\hline
\end{tabular}

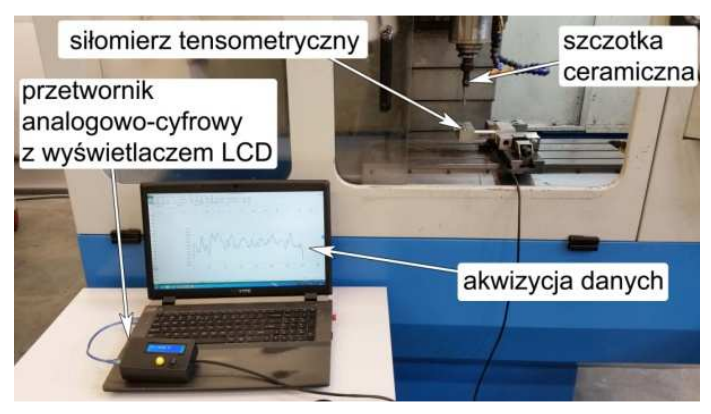

Rys. 1. Widok stanowiska badawczego

Fig. 1. View of the research stand

Siłomierz w zależności od potrzeb może być mocowany w orientacji zarówno poziomej, jak i pionowej. Sposób mocowania podczas przeprowadzonych badań zapewniał pomiar siły osiowej. Jako wzmacniacz belki tensometrycznej zastosowano 24-bitowy przetwornik analogowo-cyfrowy. Przetwornik nominalnie posiada dwie częstotliwości próbkowania: 10 oraz $100 \mathrm{~Hz}$, jednak częstotliwość można zwiększyć z zastosowaniem zewnętrznego zegara taktującego. Badania przeprowadzono z częstotliwością próbkowania $100 \mathrm{~Hz}$. Cyfrowy sygnał jest odbierany przez mikrokontroler AVR - ATmega328 i przez port COM transmitowany bezpośrednio do arkusza Microsoft Excel. Przed przystąpieniem do badań urządzenie wycechowano w zakresie dopuszczalnych obciążeń belki 
tensometrycznej, wprowadzając równanie matematyczne do mikrokontrolera, konwertujące sygnał z tensometrów belki na wartość siły.

Badania w ustalonych warunkach dla każdego rodzaju włókna oraz sprężyn powtórzono pięciokrotnie. Wyznaczono wartości średnie, odchylenia standardowe oraz amplitudę siły osiowej.

\section{Wyniki badań}

Na rysunku 2 przedstawiono wpływ rodzaju włókna szczotki na siłę osiową w procesie szczotkowania, z zastosowaniem sprężyny o małej sztywności. Wraz ze wzrostem sztywności włókien wartość siły maleje. Zauważalnie większa wartość siły dla włókien najbardziej elastycznych może być spowodowana nakładaniem się siły pochodzącej od włókien powracających podczas obróbki do swojego pierwotnego kształtu. Znacznie wyższe wartości siły oraz inną tendencję zaobserwowano podczas obróbki z zastosowaniem sprężyny o dużej sztywności (rys. 3). Niepodatne na odkształcenia włókna niebieskie powodowały większe ugięcie sprężyny w uchwycie kompensacyjnym i wyższe wartości siły osiowej.

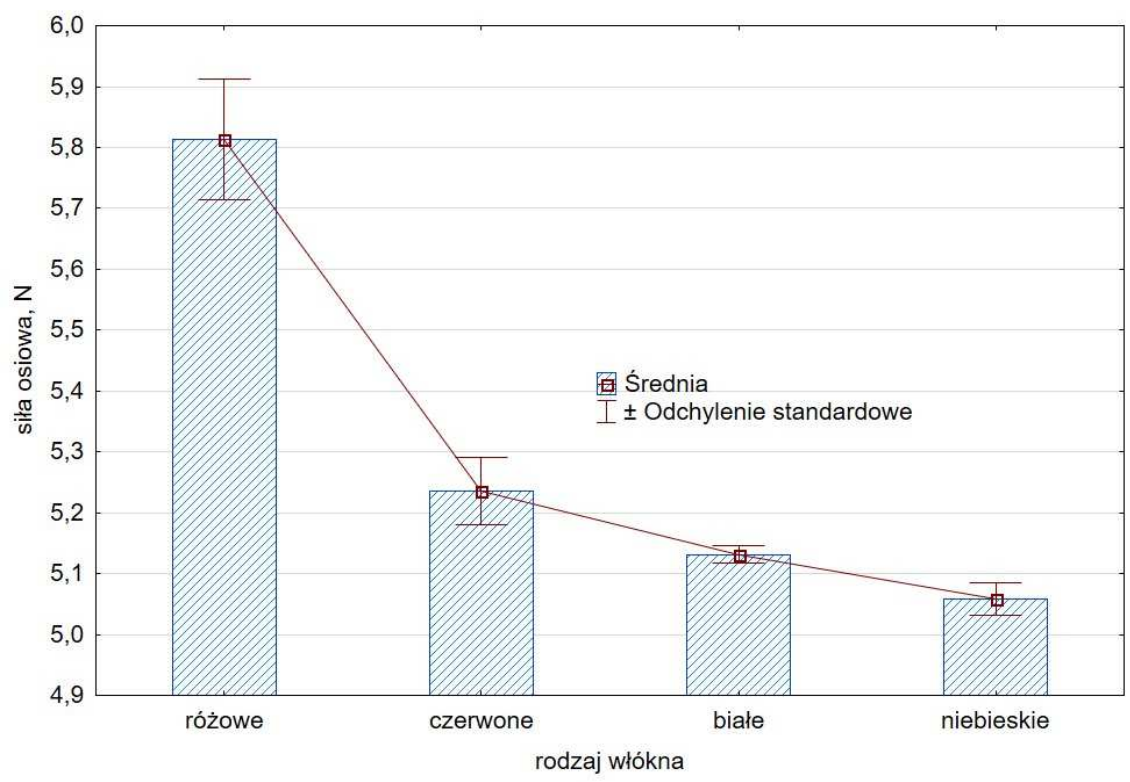

Rys. 2. Wpływ rodzaju włókna ceramicznego na siły w procesie szczotkowania (mała sztywność sprężyny)

Fig. 2. Effect of the type of ceramic fibre on forces in brushing process (low spring stiffness) 


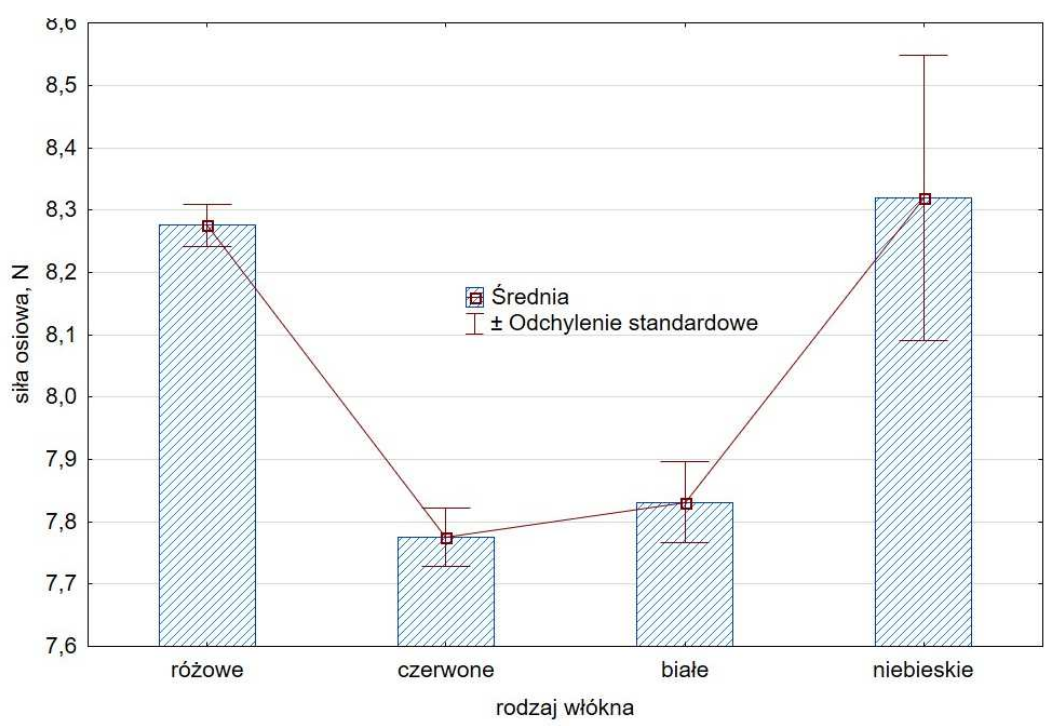

Rys. 3. Wpływ rodzaju włókna ceramicznego na siły szczotkowania (duża sztywność sprężyny)

Fig. 3. Effect of the type of ceramic fibre on forces in brushing process (high spring stiffness)

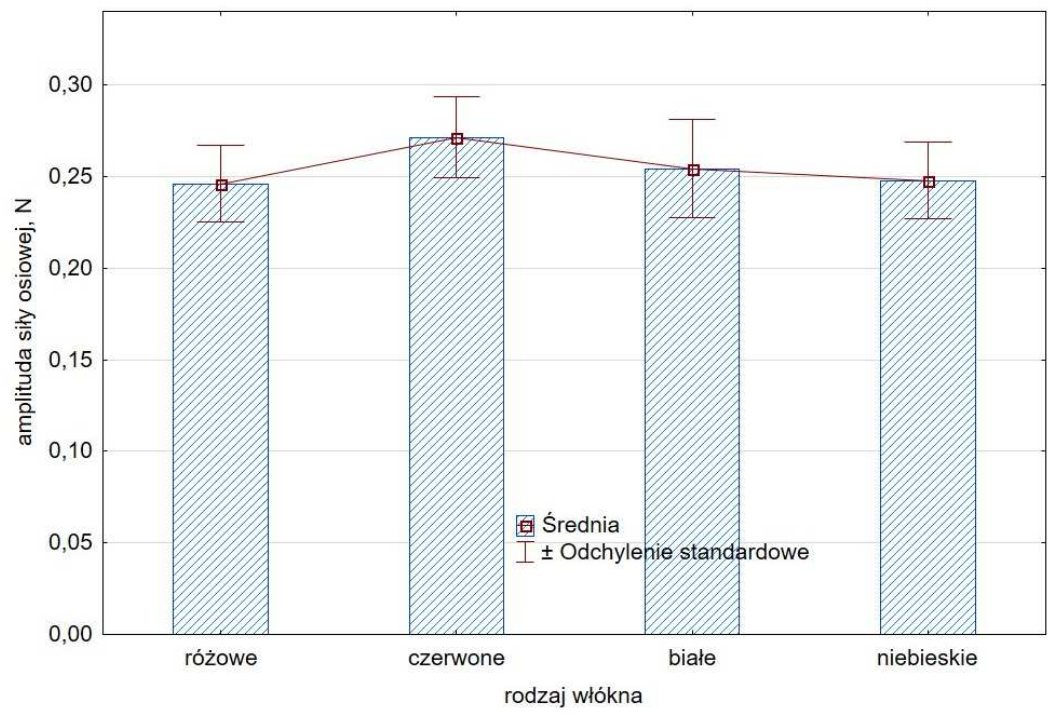

Rys. 4. Wpływ rodzaju włókna na amplitudę siły osiowej (mała sztywność sprężyny)

Fig. 4. Effect of fibre type on axial force amplitude (low spring stiffness)

Na rysunkach 4 i 5 przedstawiono wpływ rodzaju włókna szczotki na amplitudę siły osiowej odpowiednio dla sprężyny o małej i dużej sztywności. W przy- 
padku włókien różowych i sprężyny o dużej sztywności w uchwycie kompensacyjnym zaobserwowano niższe wartości amplitudy siły osiowej w porównaniu z pozostałymi włóknami.

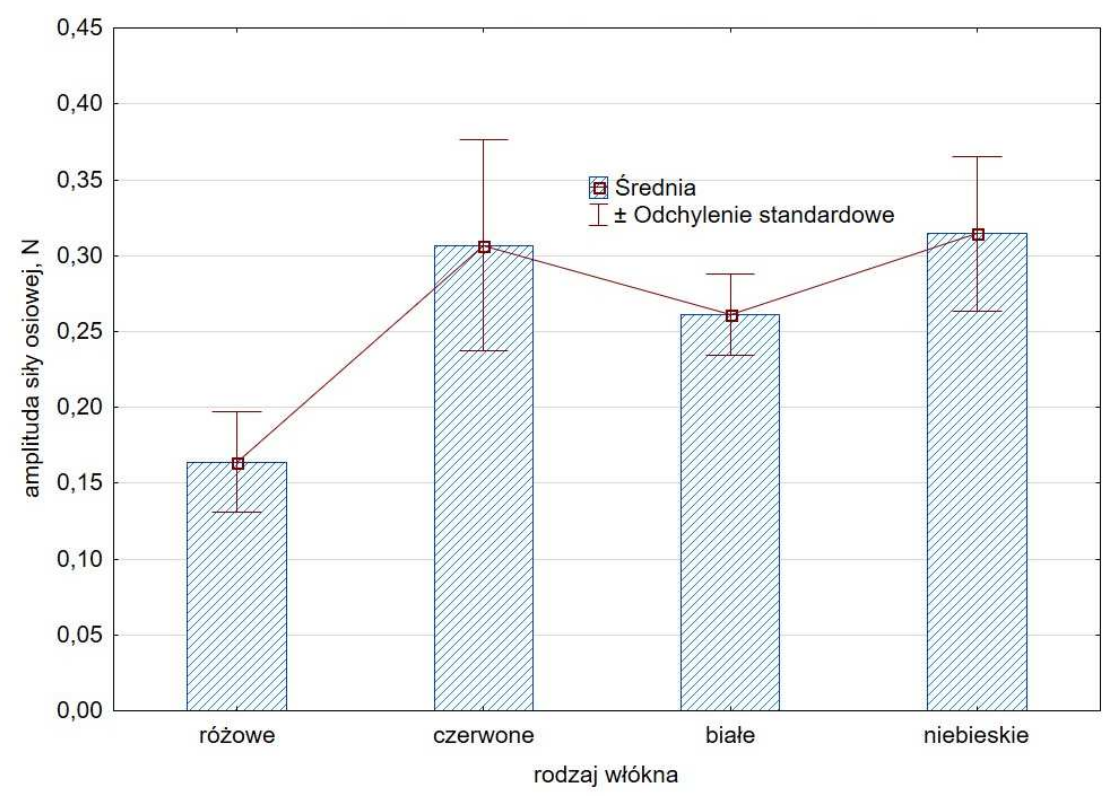

Rys. 5. Wpływ rodzaju włókna na amplitudę siły osiowej (duża sztywność sprężyny)

Fig. 5. Effect of fibre type on axial force amplitude (high spring stiffness)

\section{Podsumowanie}

W pracy analizowano wpływ wybranych czynników konstrukcyjnych szczotek ceramicznych na siłę osiową w procesie szczotkowania. Przeprowadzone badania eksperymentalne podsumowują następujące rezultaty:

- dla ustalonych w eksperymencie warunków procesu na wartość siły osiowej w większym stopniu wpływa rodzaj zastosowanej sprężyny w uchwycie kompensacyjnym niż rodzaj zastosowanego włókna,

- zaobserwowano wpływ rodzaju włókna na wartość siły osiowej,

- nie zaobserwowano znaczącego wpływu rodzaju włókna (z wyjątkiem włókien różowych i sprężyny o dużej sztywności) na wartość amplitudy siły osiowej.

Należy zwrócić uwagę, że zarówno siły, jak i amplitudy występujące w procesie obróbki szczotkami ceramicznymi są znacząco niższe w porównaniu z typowymi procesami obróbki skrawaniem. Może to mieć szczególne znaczenie w przypadku konieczności usuwania zadziorów z elementów cienkościennych charakteryzujących się małą sztywnością. Niskie wartości amplitudy wpływają na stabilny przebieg i mniejsze drgania w procesie obróbki. 


\section{Literatura}

[1] Aurich J.C., Dornfeld D., Arrazola P.J., Franke V., Leitz L., Min S.: Burrs - analysis, control and removal, CIRP Annals - Manuf. Technol., 58 (2009) 519-542.

[2] Cichosz P., Kuzinovski M.: Metody wykonywania fazek i gratowania krawędzi. Cz. 1, Mechanik, 84 (2011) 553-554.

[3] Cichosz P., Kuzinovski M.: Metody wykonywania fazek i gratowania krawędzi. Cz. 2, Mechanik, 84 (2011) 674-681.

[4] Gillespie L.K., Blotter P.T.: The formation and properties of machining burrs, J. Eng. Ind., 98 (1976) 66-74.

[5] Kosmol J., Dyrbuś G., Kazimierczak M., Kolka A., Lis K.: Automatyzacja fazowania i zatępiania krawędzi uzębień kół zębatych, Mechanik, 88 (2015) 66-80.

[6] Kowalski M., Kołodziej M.: Analiza wpływu warunków szczotkowania na stan warstwy wierzchniej otworów wykonanych w stopach magnezu, Mechanik, 89 (2016) 1440-1441.

[7] Lin T.-R.: Experimental study of burr formation and tool chipping in the face milling of stainless steel, J. Mat. Proc. Technol., 108 (2000) 12-20.

[8] Sałaciński T., Pająk P.: Obróbka wykończeniowa powierzchni z wykorzystaniem narzędzi ceramicznych do gratowania i polerowania, Mechanik, 88 (2015) 762-765.

[9] Secma.pl - Katalogi XEBEC, http://secma.pl/secma/index.php/katalogi-xebec (dostęp: 10.06.2017 r.).

\section{FORCE ANALYSIS DURING EDGE MACHINING USING CERAMIC BRUSH}

\section{S u m m a r y}

The formation of burrs is an inevitable part of the cutting process. Dedicated tools for deburring are brushes with ceramic fibres. There are many variable factors relating to the construction of ceramic brushes, which are selected depending on the type of the workpiece, the size of burrs and the expected machining effects. Variable factors include the type of ceramic fibre, projection of ceramic fibre from sleeve, the spring stiffness of the floating holder. In addition to variables related to the construction of the brushes, the process parameters (feed rate, cutting speed and depth of cut) can be controlled during the process. The article analyzes the influence of selected ceramic brush construction factors on the axial force in the brushing process. Cuboid samples made of 7075 aluminium alloy were used during the studies. The tests were carried out on a strain gauge with a sampling frequency of $80 \mathrm{~Hz}$. Flat surfaces of specimens perpendicular to the tool axis were subjected to brushing. It has been shown that the type of spring used in the floating holder has a greater effect on the value of axial force than the type of fibre used.

Keywords: burrs, cutting force, ceramic brushes, force amplitude

DOI: 10.7862/rm.2017.47

Przestano do redakcji: 24.08 .2017

Przyjęto do druku: 18.10.2017 